\title{
EL RETRATO DE LA CONDESA DE TRUILLAS DE AGUSTÍN ESTEVE Y MARQUÉS (1797)
}

\author{
Elisa Martín-ValdePeÑas YagüE ${ }^{1}$ \\ Universidad Nacional de Educación a Distancia (UNED)
}

\begin{abstract}
En este artículo se da a conocer el retrato de Francisca María Dávila Carrillo de Albornoz, condesa de Truillas (1732-1808), obra de Agustín Esteve y Marqués (1753-1820), pintado en 1797.

Palabras clave: Agustín Esteve y Marqués; Retrato; Condesa de Truillas; Junta de Damas de Honor y Mérito; Real Sociedad Económica Matritense de Amigos del País.
\end{abstract}

\section{THE PORTRAIT OF COUNTESS OF TRUILLAS BY AGUSTÍN ESTEVE Y MARQUÉS (1797)}

\begin{abstract}
This article discusses the portrait of Francisca María Dávila Carrillo de Albornoz, Countess of Truillas (1732-1808),
\end{abstract} by Agustín Esteve y Marqués (1753-1820), painted in 1797.

Key words: Agustín Esteve y Marqués; Portrait; Countess of Truillas; Women's Council; Royal Economic Society of Madrid.

Cómo citar este artículo / Citation: Martín-Valdepeñas Yagüe, Elisa (2018): "El retrato de la condesa de Truillas de Agustín Esteve y Marqués (1797)”. En: Archivo Español de Arte, vol. 91, núm. 361, Madrid, pp. 70-78. https:// doi.org/10.3989/aearte.2018.06

El 5 de abril de 1797, la Real Sociedad Económica Matritense de Amigos del País, durante la ceremonia convocada para la ocasión, colocó en una de las salas del Colegio de Educación de la Sociedad el retrato que había encargado de Francisca María Dávila Carrillo de Albornoz, condesa de Truillas ${ }^{2}$. Los "amigos del país" querían agradecer a la dama sus desvelos por los centros educativos que la institución tenía abiertos.

Pocos días antes, en la junta de 1 de abril Germano de Salcedo, marqués de Fuerte-Híjar, subdirector de la Matritense y presidente de la comisión nombrada al efecto, comunicó que el cuadro "se hallaba concluido a satisfacción de la comisión y en estado de colocarse cuando pareciese a la Sociedad, abonando por tesorería al profesor don Agustín Esteve 500 ducados en que se había convenido con la comisión por su trabajo"3. Unicamente faltaba enmarcar el lienzo. La inscripción, que fue elegida entre las varias propuestas por el censor José de Guevara Vasconcelos, reconocía el compromiso de la homenajeada con la corporación ${ }^{4}$ :

\footnotetext{
1 mmartinva1@alumno.uned.es /ORCID iD: http://orcid.org/0000-0003-1071-7577.

2 Agradezco a la Real e Ilustre Junta de Damas de Honor y Mérito las facilidades dadas para la realización de este artículo, en especial a Paz Queipo de Llano, y a Ana María Fernández Piquer por la realización de las fotografías.

${ }^{3}$ Libro de Actas de las Juntas de la Sociedad (1797-1798), Junta de 1 de abril de 1797, Archivo de la Real Sociedad Económica Matritense de Amigos del País (ARSEM), Libro A/110/22.

${ }^{4}$ El retrato fue reproducido en blanco y negro en San Alberto, 1925, sin indicar al pintor. Por error está fechado en 1792. Muy posteriormente apareció parcialmente sin identificación en un documental de la serie "La Aventura del
} 


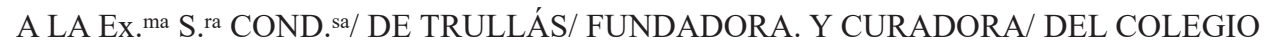
DE EDUCACION/ Y / DE LA ESCUELA DE ADORNOS/ PRESIDENTA TRES BECES/ DE LA JUNTA DE SEÑORAS DE HONOR Y MERITO:/ LA SOCIEDAD ECONOMICA/ DE MADRID / POR LOS BENEFICIOS RECIBIDOS/ ACORDÓ Y COSTEO/ ESTA SEÑAL DE SV AGRADECIMTO/ AÑO DE 1797.

Los días 5 y 6 de abril por la tarde se celebrarían los exámenes de las alumnas del Colegio de Educación. A los socios de la Matritense les pareció que era la ocasión idónea para la colocación y descubrimiento del retrato. Los miembros de la institución fueron invitados mediante esquelas y se escribió a la condesa de Montijo, María Francisca de Sales Portocarrero, secretaria de la Junta de Honor y Mérito, para que las señoras también asistieran al acto ${ }^{5}$.

El lienzo había sido encargado poco tiempo antes a Agustín Esteve y Marqués (1753-1820). El valenciano gozaba de prestigio entre las elites madrileñas de finales del siglo XVIII como pintor de retratos especialmente femeninos en los que "alcanzó efigies de una gran elegancia y refinamiento". Desde 1780 era ayudante de Francisco de Goya, cuya influencia -además de la de Rafael Mengs, que sobrevolaba sobre todos los pintores de la época- resulta apreciable en su producción artística. Algunos retratos oficiales de los reyes, destinados a proveer a diversos organismos públicos desde su coronación en 1788, fueron copias ejecutadas por Esteve a partir de las pinturas reales del insigne aragonés que, abrumado por el exceso de trabajo, derivaba a su colaborador los trabajos que no podía cumplir ${ }^{6}$.

Martín S. Soria, que no incluyó este cuadro en su clásico e imprescindible trabajo sobre Esteve, insistió en su habilidad como "pintor de señoras y niños", debido a que "Su talento encajaba bien para mostrar la dulzura de un niño pequeño o la delicadeza de una dama joven y elegante". Al analizar los cuadros que podrían atribuírsele con mayor probabilidad, apuntó algunas características propias de su estilo: la disposición de las figuras en agradable pero convencional actitud; la expresión de los rostros, con alguna rigidez en la sonrisa y los característicos "ojos oscuros"; los fondos con cortinajes y la ausencia de contrastes, produciendo cierta vaguedad en el modelado; la suave y uniforme iluminación; y el uso de los brillos que "producían un seductor y esmaltado efecto de extremada sensibilidad". En la época en que ejecutó el retrato de la condesa de Truillas, en el que se pueden apreciar todos estos rasgos distintivos, se hallaba en la cima de su carrera al ser "considerado el pintor favorito de la sociedad madrileña"7.

En la pintura (fig. 1) la dama en cuestión, que contaba con 63 años, aparece en el centro del cuadro con un vestido negro, largo y abombado desde la cintura. La media manga por debajo del codo está ribeteada con blondas fruncidas y onduladas con dos vueltas. Cubre la parte superior del pecho hasta el cuello con un pañuelo de muselina prendido al vestido y rematado también con blondas. Porta la banda de la Orden de Damas Nobles de la reina María Luisa compuesta por tres franjas, la central blanca y las dos laterales moradas, cruzada desde hombro derecho al costado izquierdo, y está atada con un lazo que sujeta la insignia o venera, consistente en una cruz de ocho puntas de oro con un óvalo en el centro. Su mano derecha está levantada, apoyada en el emblema de la Real Sociedad Económica Matritense en el que se puede leer su clásico lema:

\footnotetext{
Saber" con el título "La Inclusa de Madrid" producido por la UNED y dirigido por la profesora Florentina Vidal Galache en 1999. El documental de 16:54 minutos de duración puede consultarse en el Canal UNED de Televisión Educativa. https://canal.uned.es/mmobj/index/id/10586. En el Instituto de Patrimonio Cultural de España se conserva una fotografía en blanco y negro del cuadro, probablemente del primer tercio del siglo XX, en cuya ficha de catalogación figura Agustín Esteve como autor de la pintura (Condesa de Trullas, Agustín Esteve, 1796, Casa de Maternidad (Madrid), Fototeca de Patrimonio Histórico, Archivo Casa Moreno. Archivo de Arte Español (1893-1953), 07943_B. http:// ipce.mecd.gob.es/documentacion/fototeca.html.

5 Sobre la Real Sociedad Económica Matritense de Amigos del País y la Junta de Honor y Mérito existe bastante bibliografía. Para conocer las circunstancias de su fundación y el papel de ambas instituciones en la época de la Ilustración especialmente en el aspecto educativo, véase Negrín, 1987.

${ }^{6}$ Lafuente, 1957: 24. Soria, 1957: 35-36.

7 Soria, 1957: 54 y 64.
} 


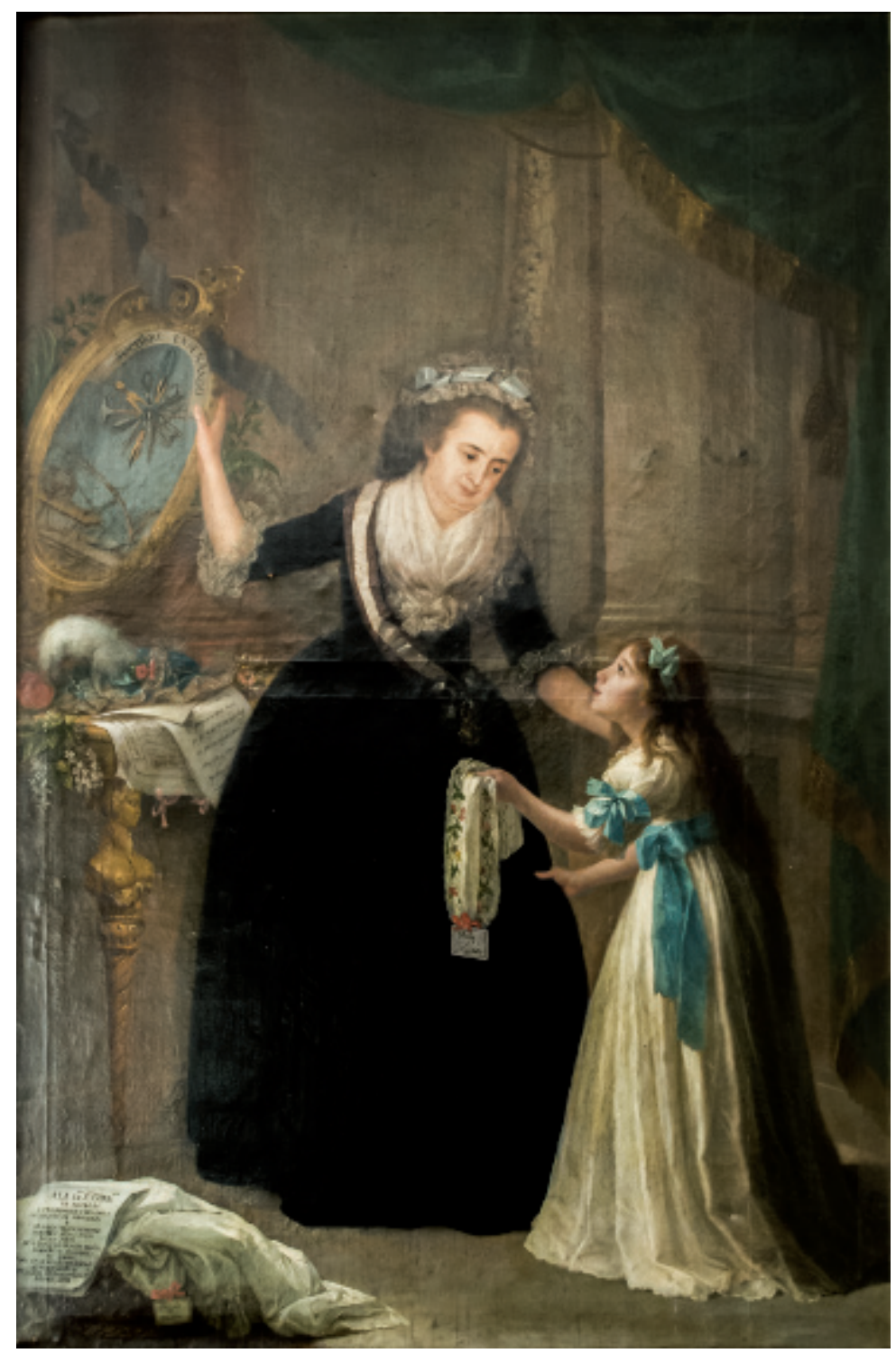

Fig. 1. Agustín Esteve y Marqués. Retrato de Francisca María Dávila Carrillo de Albornoz, condesa de Truillas. 1797. Óleo sobre lienzo. $214 \times 138 \mathrm{~cm}$. Real e Ilustre Junta de Damas de Honor y Mérito. Madrid. (Fotografía: Ana María Fernández Piquer).

"Socorre Enseñando" (fig. 2) y la izquierda descansa sobre el hombro de una niña a la que mira de soslayo. El pelo de la dama está recogido en una especie de cofia con ribete de encaje o blonda ondulada y una gran cinta de tejido que da varias vueltas.

La muchacha, a la derecha, le presenta una muestra de tejido blanco con labores de bordado de hojas y flores amarillas y rosas con una cartela o esquela sujeta al tejido por una cinta rosa anudada con lazos en la que figura "Premio/ 3.\% Bordado", referencia inequívoca a los exámenes anuales de los centros de formación profesional, cuyas ceremonias de celebración y entrega de premios, constituían la forma en la que la Sociedad Económica y la Junta de Damas se proyectaban públicamente.

Destaca la dulzura de los rasgos de la joven que eleva la cabeza hacia a la dama, mirándola fijamente, y agarra con su mano derecha el traje negro de la condesa tratando de captar su atención, así como la delicadeza de Esteve al pintar su elegante y largo vestido blanco, sobre todo en los detalles: las mangas con tablillas, el escote con un minúsculo ribete de encaje y el final del largo de la prenda que cae con ligereza al suelo, terminado en adorno de festón. Como contraste, a la altura de la cintura, la muchacha lleva una faja azul celeste ceñida por un gran lazo. La 


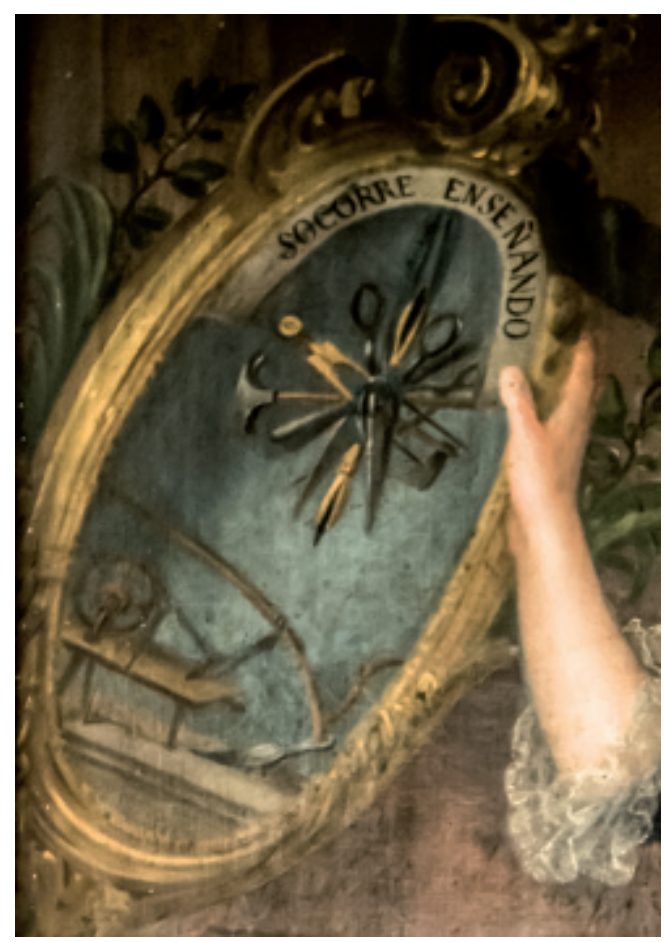

Fig. 2. Detalle (Fotografía: Ana María Fernández Piquer).

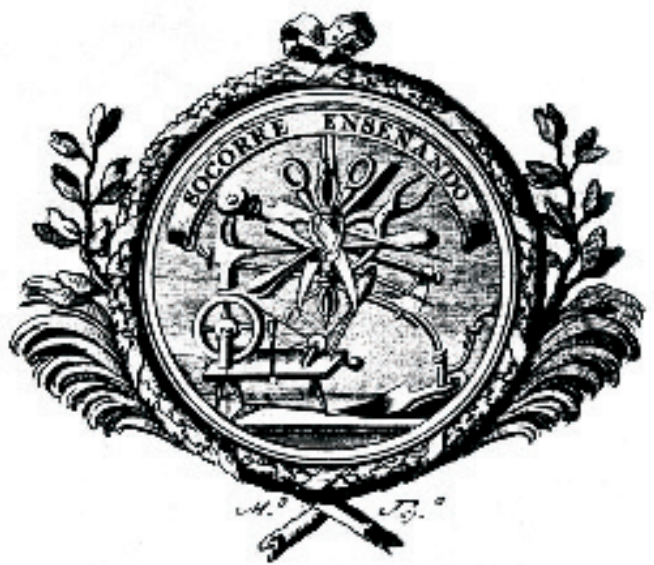

Fig. 3. Emblema de la Real Sociedad Económica Matritense de Amigos del País. Portada del Reglamento para la Escuela de Encajes. Madrid. 1784.

abombada manga del vestido, también está adornada con un lazo del mismo color. Su pelo largo y suelto está sujeto únicamente con una cinta anudada en un tono verdoso a modo de diadema.

El fondo, bastante oscuro, simula la pared del interior de una habitación, sin apenas contrastes, salvo una pilastra, con su moldura y se adivina una guirnalda estucada en el tabique trasero. En la parte superior derecha del cuadro se abre un cortinaje verde ribeteado con una banda de flecos dorados recogido con un cordón rematado por dos borlas que llega hasta el borde inferior, ondulándose en la caída.

El emblema de la Sociedad que venía reproduciéndose sin apenas variantes en las publicaciones desde su fundación, fue diseñado siguiendo la premisa que fijaban los estatutos de 1775 (fig. 3). El título XV aludía a que se había elegido "una medalla en que estén los símbolos de la agricultura, industria y artes". El diseño circular, elegido por una comisión de tres socios, representaba un conjunto de instrumentos sujetos por una cinta suspendida de la parte superior entre los que se encuentran unas tijeras, un compás, un martillo, una lima, unas tenazas, un hacha y un tiralíneas. En la parte de abajo, un banco de hilar con torno y rueca y un arado. Todo ello enmarcado con una guirnalda de hojas de roble envueltas con una cinta coronada por un lazo y rodeada con motivos vegetales, dos ramas de laurel y dos de palma. En la parte interior de círculo, arriba, aparecía el lema de la Matritense ${ }^{8}$. En el cuadro, el escudo de forma ovalada, figura a la izquierda inclinado y aparentemente sostenido en la parte superior por una ancha banda negra ondulada que pende de la pared.

8 Real Cédula, 1775: 42. Una variante de este grabado, que suele aparecer en las publicaciones de la corporación durante el siglo XVIII y principios del siglo XIX, representa a una matrona de perfil sentada que apoya su brazo izquierdo sobre una medalla con el emblema de la sociedad y que sostiene en la derecha una rama de olivo. El grabado se completa con el dibujo de un conejo a sus pies y a su espalda motivos vegetales simulando un arbusto. González, 1996: $257-258$ 


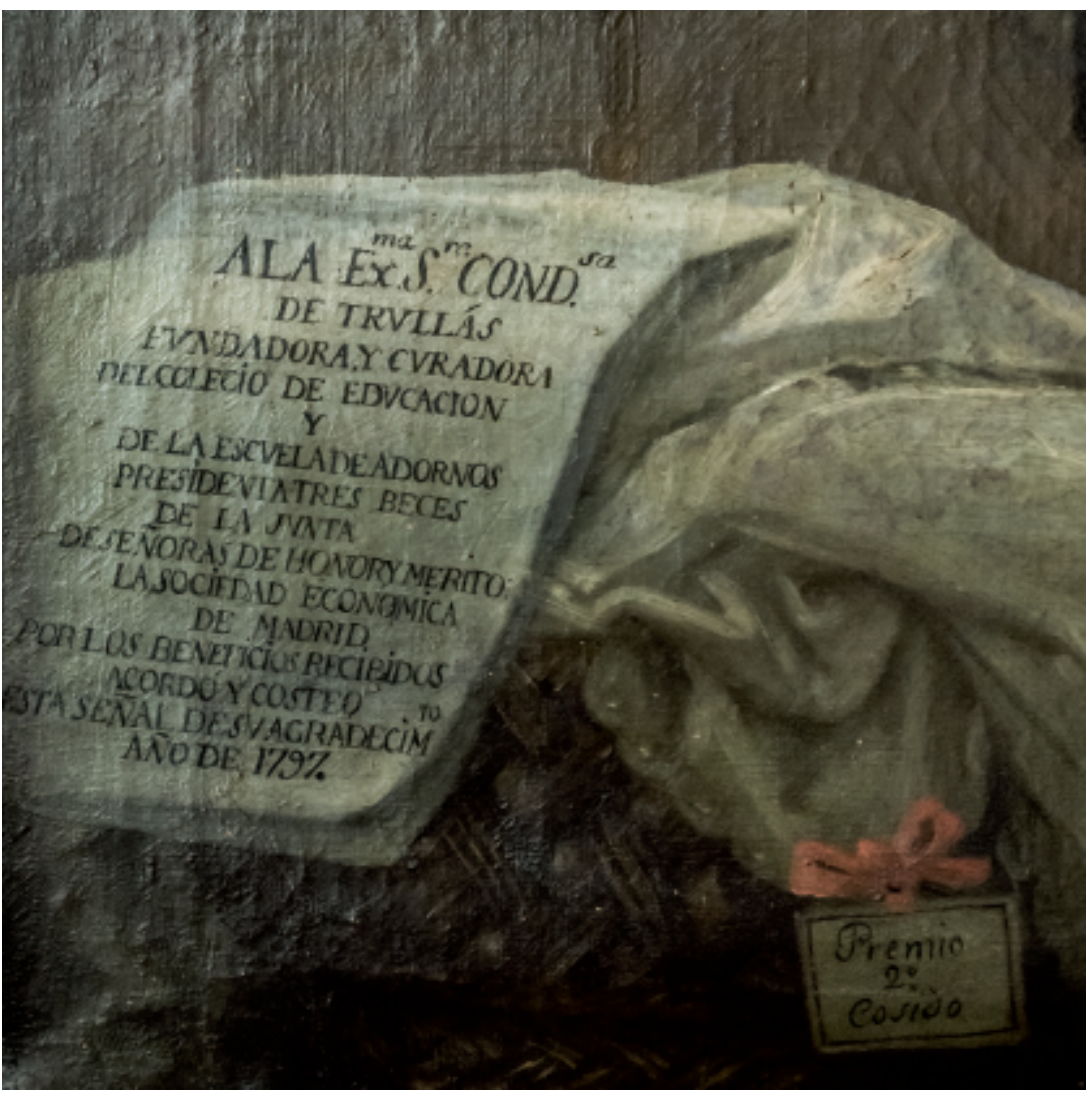

Fig. 4. Detalle (Fotografía: Ana María Fernández Piquer).

En la parte de la izquierda del lienzo debajo del emblema se sitúa una mesa llena de papeles, muestras de gasas, encajes, plumas y flores artificiales, simulando el escritorio de trabajo de la presidenta de la Junta de Damas ${ }^{9}$. La institución femenina tenía a su cargo varios centros de formación profesional para niñas, entre ellas, las Escuelas Patrióticas, la de Bordados, Flores Artificiales y el Colegio de Educación donde las alumnas aprendían este tipo de labores. La única pata visible de la mesa está finamente adornada con una cariátide esculpida hasta el pecho adoptando forma cónica invertida acanalada, disminuyendo el grosor hacia la parte inferior. Debajo, en el suelo, un cesto que contiene una gran tela blanca arrugada, sobresaliendo por los bordes, con la esquela prendida al tejido con una cinta rosa en la que se lee "Premio/ 2.\% Cosido". Encima descansa un papel colocado sobre la tela, donde está escrito el letrero con los datos de la protagonista del lienzo ya aludido (fig. 4).

Mientras que, para el análisis de otros retratos femeninos de Esteve, el contexto en el que se realizó el encargo puede resultar poco relevante, más allá de la personalidad de la retratada, en este caso, al tratarse de un cuadro institucional, para su estudio resulta necesario aportar unas breves pinceladas sobre la dama, el establecimiento que lo encargó, el centro al que estaba destinado y la ceremonia que se celebró para la colocación de la pintura.

Francisca María Dávila Carrillo de Albornoz era la presidenta de la Junta de Honor y Mérito desde finales de septiembre de 1790, cuando fue elegida en sustitución de la anterior, la duquesa

${ }^{9}$ Entre los papeles desperdigados por la mesa aparece un estadillo con la leyenda: "Premios./ Escuela de la R. Sociedad/ curadora la S. Condesa de Trullás" y el fragmento de un papel en el que se puede leer la frase "El perezoso no quiso traba/ jar por el frío y así mendigó/ sin socorro alguno en el be/ rano y en el estío", probable referencia a uno de los Proverbios del rey Salomón: "Proper frigus piger arare noluit: mendicabit ergo aestate, et non dabitur illi" (Proverbia: XX, 4). 
de Osuna. Había nacido en Vélez-Málaga el 21 de agosto de 1733. Sus padres fueron José Lorenzo Dávila Tello de Guzmán y María Magdalena Carrillo de Guzmán y Antich, condes de Valhermoso y, a partir de 1747, duques de Montemar ${ }^{10}$. A los diecinueve años, el 15 de mayo de 1753, contrajo matrimonio en Madrid con Alonso Ignacio Verdugo y Castilla, conde de Torrepalma, escritor y diplomático ${ }^{11}$.

El conde de Torrepalma era un hombre con ambiciones intelectuales, partícipe y animador de la vida cultural madrileña. Perteneció a la Real Academia Española, a la de Bellas Artes de San Fernando, fue uno de los fundadores de la de la Historia en 1735, de la que llegó a ser presidente en 1740, y también de la informal Academia del Buen Gusto, presidida por la marquesa de Sarriá. En septiembre de 1754, fue nombrado ministro plenipotenciario en Viena, a donde llegó en agosto del año siguiente ${ }^{12}$. Posteriormente, en julio de 1760 se trasladó a Turín como responsable de la legación en aquella corte. Allí fallecería el 25 de marzo de $1767^{13}$. Tras la muerte de su esposo, al que acompañó en sus destinos diplomáticos, Francisca María regresó a Madrid.

El 24 de agosto de 1776 en la Capilla Real del Real Sitio de San Ildefonso en Segovia, Francisca María contrajo matrimonio secreto con Antonio Ricardos y Carrillo de Albornoz, su primo hermano, tras solicitar la oportuna dispensa papal por parentesco ${ }^{14}$. El contrayente fue un distinguido militar, miembro fundador de la Real Sociedad Económica Matritense, teniente general e inspector de Caballería. En 1775 fundó el Real Colegio Militar de Caballería y Picadero de Ocaña donde los alumnos recibían formación militar con novedosos métodos pedagógicos ${ }^{15}$. Al mando del ejército en la primera campaña de la Guerra de la Convención contra los revolucionarios franceses, el 22 de septiembre de 1793 les infringió una seria derrota en la batalla de Truillas, en el Rosellón. Falleció en Madrid el 13 de marzo de $1794^{16}$.

Francisca María desempeñó varios puestos palatinos. Fue nombrada aya del infante Carlos Clemente (1771) y posteriormente de otros hijos de los reyes: María Luisa (1782), los infantes gemelos, Carlos y Felipe (1783), y del futuro Fernando VII (1784). En 1794 se le otorgó la banda de la Orden de Damas Nobles de la reina María Luisa. El título de condesa de Truillas le fue

10 José Lorenzo Dávila Tello de Guzmán (Sevilla, 1710-Madrid, 1750), alcanzó el grado de teniente general de los Reales Ejércitos y fue comandante de la Brigada de Carabineros Reales. Casó en 1729 con María Magdalena Carrillo de Albornoz y Antich (Viso del Marqués, 1707-Madrid, 1790), hija de José Carrillo de Albornoz y Montiel, primer duque de Montemar. El Museo del Prado conserva un dibujo de un monumento funerario en su memoria para la iglesia de San Vicente de Sevilla encargado por su hermana Ana (Túmulo funerario en honor a José Dávila Tello de Guzmán, duque de Montemar, Pedro Tortolero, 1750, Museo del Prado, G05607). Tuvieron dos hijas, María Josefa (1730-1785), casada en 1750 con Joaquín Lorenzo Ponce de Léon y Baeza (1731-1807), marqués de Castromonte, y Francisca María.

${ }^{11}$ El matrimonio se celebró en la residencia de los padres de Francisca María en la calle Leganitos de Madrid. Partida de matrimonio de Alonso Verdugo y Castilla y Francisca María Carrillo de Albornoz, 15 de mayo de 1753, Archivo Histórico Diocesano de Madrid (AHDM), Parroquia de San Martín, Libro 23: Matrimonios (1752-1756), fols. $163 \mathrm{v}$ y 164. Alonso Verdugo y Castilla, señor de Gor y conde de Torrepalma, nació en Alcalá la Real (Jaén) el 3 de septiembre de 1706. El 23 de abril de 1747 casó en Madrid con Josefa Ignacia Bernuy Hinestrosa, hija de los marqueses de Benamejí, con la que tuvo dos hijos: Pedro Antonio (1748-1750) e Isabel María (1749-1751). Su esposa murió en Madrid el 7 de diciembre de 1750. Su hermana Ana Verdugo y Castilla (1696-1771), religiosa conocida con el nombre de Ana de San Jerónimo, también fue una notable poetisa cuya vida trascurrió en el convento del Ángel Custodio de Granada de la orden de San Francisco.

12 Sobre la actividad diplomática del conde de Torrepalma en Viena, véase Marín, 1958.

13 Marín, 1971: 28-75, 82 y 97. Ozaman, 1998: 463-464.

${ }_{14}$ Antonio Ricardos y Carrillo de Albornoz nació en Barbastro (Huesca) el 12 de septiembre de 1727. Era hijo de Felipe Ricardos Rodríguez de Herrera y Leonor Carrillo de Albornoz y Antich, hermana de María Magdalena Carrillo de Albornoz y Antich, la madre de Francisca María Dávila. En el Museo del Prado se conserva un retrato del general Ricardos, obra de Goya, regalado por su viuda a Manuel Godoy (El General Antonio Ricardos, Francisco de Goya y Lucientes, 1793, Museo del Prado, P02784). Véase Rose, 1980.

15 Martínez, 1988: 65. Nieto, 1946: 120.

16 La Sociedad Económica Matritense encargó el elogio fúnebre a José Martínez de Hervás (años más tarde conocido como marqués de Almenara, ministro del Interior de José Bonaparte). El elogio se publicó en 1795 en el V tomo de las Memorias de la Sociedad Económica de Madrid junto al Informe sobre la Ley Agraria de Jovellanos. 
concedido de forma vitalicia el 30 de marzo de 1794 tras el fallecimiento del general Ricardos, "en memoria de la batalla ganada en aquel sitio por su segundo marido"17.

La dama se incorporó a la Junta de Honor y Mérito el 7 de diciembre de 1787, dos meses después de la inauguración oficial de la asociación femenina. Fue elegida vicepresidenta el 2 de mayo de 1788. Durante once años, de 1790 a 1801, ejerció el puesto de máxima responsabilidad de la institución y, posteriormente, en los años de 1804 a 1805 volvió a desempeñar la vicepresidencia. A ella se le deben algunos informes como el del establecimiento de una escuela de modas (1788), sobre las escuelas de hilados (1790), sobre una fábrica de gasas (1793), sobre alfombras (1793), además de diversas memorias anuales en las que daba cuenta de su gestión como presidenta ${ }^{18}$. En 1795 organizó los trabajos para el funcionamiento de las comisiones de educación, establecidas por los estatutos de la Junta de Damas aprobados en 1794. Como presidenta de la sección de educación moral, escribió una memoria sobre "la instrucción que de la religión debe darse a las mujeres en su educación" que leyó al resto de socias el 9 de octubre de $1795^{19}$. Además, fue la autora del primer "Elogio" a la reina María Luisa -una colección de escritos laudatorios escritos por las socias de la sección femenina de la Matritense entre 1794 y 1801-que fue leído en la junta pública de la Sociedad el 25 de enero de 1794 y posteriormente impreso ${ }^{20}$.

En 1796 formó parte de la comisión de la Junta de Damas que fue autorizada por el rey para visitar la Inclusa. En 1799 consiguió que la citada asociación femenina se hiciera cargo de la supervisión del orfanato e influyó, junto a la condesa de Montijo, para el reconocimiento legal de los expósitos. En 1801 el rey encargó a la condesa de Truillas de la reorganización del Colegio de Niñas de la Paz, fundado por la duquesa de Feria en 1679 para las niñas abandonadas. Por la Real Orden de 1 de septiembre de 1807, las damas obtuvieron la dirección de este centro educativo $^{21}$. Francisca María Dávila también perteneció a la Real Asociación de Caridad de Señoras, otra asociación de carácter filantrópico que actuaba en las cárceles femeninas.

En 1805, la condesa perdió el favor de los reyes debido a sus contactos con los grupos opositores afines al Príncipe de Asturias. Murió en Calatayud el 24 de enero de 1808, donde había sido desterrada tres años antes.

Las dos instituciones implicadas en el acto, la Real Sociedad Económica Matritense de Amigos del País y la Junta de Honor y Mérito son suficientemente conocidas, pero no lo es tanto el Colegio de Educación de la Sociedad o Escuela de Modas, donde se colocó el retrato. Constituyó la experiencia pedagógica más compleja y ambiciosa de la corporación madrileña que había intentado varias veces fundar una escuela que uniese varias enseñanzas profesionales en un solo centro, sin éxito. La condesa de Torrepalma fue la encargada de elaborar un proyecto definitivo para su establecimiento, después de que los "amigos del país" y las damas llegaran a un acuerdo por el que los primeros aportarían la cantidad de dinero suficiente para su instalación y mantenimiento. Tras solicitar al gobierno la dotación necesaria, que estaría en torno a 1.500 ducados anuales, el conde de Floridablanca comunicaba que, por la Real Orden de 18 de mayo de 1790, el rey había aprobado la subvención. El Colegio fue inaugurado dos meses más tarde, en julio. Funcionaba como un internado privado en el que a las alumnas se les proporcionaba la enseñanza, el alojamiento y la manutención por cuatro reales diarios y también se admitían niñas externas. Se organizaba en dos clases, la de costura y la de adornos. Las jóvenes recibían formación elemental: lectura, escritura, cuentas y religión ${ }^{22}$.

En agosto de 1790 Francisca María Dávila elaboró el reglamento de funcionamiento de centro en el que daba especial importancia a la higiene, a la formación moral y a las actividades

17 Mercurio de España, III-1794, 352-353; IV-1794, 421-422; VIII-1794, 474.

18 Rueda/Ríos/Zábalo, 1989: 117. San Alberto, 1925.

19 Véase el Título VIII de los Estatutos, 1794: 30. Informe del censor sobre el mérito de las siete Memorias formadas por la Señoras en sus Comisiones de Educación Física y Moral, 14 de marzo de 1801, ARSEM, Expediente 146/11. Negrín, 1987: 144.

20 Torrepalma, 1794.

21 Vidal, 1994: 58-62, 162-163 y 218-219.

22 Diario de Madrid, 206, 25-VII-1790: 826. Demerson, 1972: 202-203. Negrín, 1987: 211. 
lúdicas. También resulta muy detallado en cuanto a los horarios que debían seguir las educandas y presta especial importancia a la enseñanza de la religión. "No es extraño el acatamiento general de este reglamento a la finalidad básica del colegio: la formación de mujeres según el arquetipo tradicional de cristianas, esposas, amas de casa, etc." ${ }^{23}$. En 1794 el Colegio contaba con 99 alumnas, cantidad que se mantuvo los años siguientes. La fundación escolar, a pesar de todas las vicisitudes por las que pasó, consiguió permanecer abierta hasta mediados de 1812 en plena guerra de la Independencia. La penuria, la falta de financiación y las deudas acumuladas obligaron a su clausura definitiva ${ }^{24}$.

En la ceremonia de descubrimiento del retrato, el 5 de abril de 1797, el subdirector de la Matritense, el marqués de Fuerte-Híjar, leyó un discurso en el que exaltaba la acción de la condesa de Truillas que había conseguido 40.000 reales para que el Colegio de Educación sobreviviese, cuando la Sociedad había perdido la esperanza ${ }^{25}$. La institución agradecía sinceramente semejante gesto. Según el acta de la reunión la ceremonia produjo en todos los presentes

vivos sentimientos de ternura, y júbilo; porque de un lado se les representaban las acciones virtuosas de la persona a quien se ofrecía aquel tributo de reconocimiento, y gratitud, y del otro la ilustración, y generosidad de la Real Sociedad, que conociendo, y apreciando justamente los beneficios, que la proporcionan sus individuos sabe también corresponder a ellos dignamente, erigiendo monumentos que perpetúen su memoria en los siglos venideros ${ }^{26}$.

El subdirector animó a las alumnas que rogasen por la larga vida de su protectora. Ella, emocionada y "no pudiendo por esta razón manifestar con palabras todo su reconocimiento por esta singular demostración", se limitó a contestar que

aquellas tiernas Jóvenes dirigidas, y educadas bajo su protección, y cuidado serían en todo tiempo el mejor testimonio de su agradecimiento a las muy señaladas mercedes de la Real Sociedad a la cual procuraría proporcionar en adelante todos los alivios, y prosperidad, que la fuesen posibles con la misma actividad, y patriotismo con que lo había hecho hasta ahora ${ }^{27}$.

En efecto, así ocurrió. Si las escuelas a cargo de la Junta de Damas pudieron sobrevivir en esta época se debió a la diligente actividad de Francisca María Dávila que en repetidas ocasiones consiguió que Manuel Godoy, el rey y la reina se sensibilizaran con las necesidades financieras de estos centros concediendo ayudas extraordinarias ${ }^{28}$.

23 Torrepalma, [1790] 1984: 113-119. Negrín, 1987: 213 у 217.

24 Martín-Valdepeñas, 2010: 181.

25 El cuadro se colocó en el "testero principal de la Sala de la Habitación de Pupilas" del Colegio de Educación que estaba situado en la calle de Segovia esquina a la plaza de la Cruz Verde y a calle del Estudio en Madrid. Después de su cierre en 1812, el cuadro presidió durante prácticamente un siglo la sala de reuniones de la Junta de Damas en la Real Inclusa de Madrid situada en la calle Mesón de Paredes y posteriormente, tras la inauguración del Colegio de Niñas de la Paz en 1929, fue trasladado a la nueva sede en el complejo de edificios asistenciales que la institución femenina poseía en la manzana entre las calles O'Donnell y doctor Esquerdo de la capital. Libro de Actas de la Junta de Damas (1797-1798), Junta de 5 de abril de 1797, ARSEM, Libro A/56/5.

${ }^{26}$ El marqués de Fuerte-Híjar insistió en el compromiso de la condesa con los establecimientos educativos: "Vosotras inocentes criaturas levantad vuestras tiernas manos al cielo, y pedidle a nombre [de] la Sociedad; al vuestro, y al de tantos como gozan felizmente del Patriotismo de esta Señora que prolongue su vida cuanto permita la mortal miseria, y que después de sus días, inmortalizándose este retrato os recuerde sin cesar sus beneficios, y os presente constantemente sus ejemplos". Libro de Actas de las Juntas de la Sociedad (1797-1798), Junta de 5 de abril de 1797, ARSEM, Libro A/110/22.

27 Al día siguiente, en el que continuó la celebración de los exámenes de las alumnas, Francisca María Dávila, aprovechando la gran concurrencia de socias y socios, volvió a manifestar su reconocimiento por el retrato por medio de un discurso leído por Juan Salustiano Zamorano. Libro de Actas de las Juntas de la Sociedad (1797-1798), Junta de 5 de abril de 1797, ARSEM, Libro A/110/22. Libro de Actas de la Junta de Damas (1797-1798), Junta de 6 de abril de 1797, ARSEM, Libro A/56/5.

${ }^{28}$ Demerson, 1972: 201. 
El retrato de María Francisca Dávila de Agustín Esteve y Marqués, realizado en los años cumbre de su carrera, constituye una muestra indiscutible de la elegancia de su pintura. El lienzo combina la esmerada y preciosista ejecución, la recreación en los detalles, la pureza de las líneas, la sutileza en el color y la tenue luminosidad, muy características de su estilo pictórico, con la delicadeza que trasmiten las figuras femeninas. La habilidosa y cuidadosa mano del artista consiguió dotar al conjunto de equilibrio, sin perder de vista la simbología que envuelve a la retratada, impuesta por el encargo institucional. Este cuadro amplía el catálogo artístico del pintor valenciano, que eclipsado en parte por la grandeza y genialidad de su amigo Francisco de Goya, precisa de nuevos análisis que revaloricen su importancia como retratista.

\section{BIBLIOGRAFÍA}

Demerson, Paula de (1972): “Las Escuelas Patrióticas entre 1787 y 1808”. En: VV.AA. (1972): Las Reales Sociedades Económicas de Amigos del País y su obra. San Sebastián: CSIC, pp. 191-205.

Estatutos de la Junta de Honor y Mérito de la Real Sociedad Económica de Madrid (1794). Madrid: Imprenta de Sancha.

González Echegaray, Carlos (1996): "Reseña histórica de los emblemas de la Sociedad Matritense”. En: Torre de los Lujanes, 31, Madrid, pp. 257-260.

Lafuente Ferrari, Enrique (1957): "Prólogo”. En: Soria, Martín S.: Esteve y Goya. Valencia: Institución Alfonso el Magnánimo-Diputación Provincial de Valencia, pp. 15-28.

Marín López, Nicolás (1958): "El conde de Torrepalma, ministro plenipotenciario en Viena (1755-1760)". En: Cuadernos de Historia Diplomática, IV, Zaragoza, pp. 155-175.

Marín López, Nicolás (1971): Poesía y poetas del setecientos. Granada: Universidad de Granada.

Martín-Valdepeñas Yagüe, Elisa (2010): "Beneficencia y mujeres en tiempos de guerra: La Junta de Honor y Mérito (1808-1814)". En: Torre de los Lujanes, 67, Madrid, pp. 175-218.

Martínez de Hervás, José (1795): "Elogio del Excelentísimo Señor D. Antonio Ricardos Carrillo de Albornoz". En: Memorias de la Sociedad Económica de Madrid. Tomo V. Madrid: Imprenta de Sancha, pp. 1-27.

Martínez Fernández, Mateo (1988): "Ricardos y la Academia de Caballería de Ocaña”. En: Revista de Historia Militar, 65, Madrid, pp. 61-95.

Negrín Fajardo, Olegario (1987): La educación popular en la España de la segunda mitad del siglo XVIII. Madrid: UNED.

Nieto Lanzos, Abelardo (1946): El general Ricardos. Madrid: Editorial Gran Capitán.

Ozaman, Didier (1998): Les diplomates espagnols du XVIII siècle. Introduction et répertoire biographique (1700-1800). Madrid-Bourdeaux: Casa de Velázquez- Maison des Pays Ibériques.

Real Cédula de S. M. y Señores del Consejo, en que se aprueban los Estatutos de la Sociedad Económica de Amigos del País (1775). Madrid: Imprenta de Pedro Marín.

Reglamento para la Escuela de Encajes, establecida en virtud de Real Orden de S. M. en el Monte Pío de la Real Sociedad Económica de Madrid (1784). Madrid: Imprenta de Antonio Sancha.

Rose, Isadora (1980): "Sobre el retrato del General Ricardos que pintó Goya". En: Academia: Boletín de la Real Academia de Bellas Artes de San Fernando, 50, Madrid, pp. 115-123.

Rueda Roncal, Ana, Ríos Izquierdo, Pilar y Zábalo Rojas, María Esperanza (1989): “Carlos III y la Junta de Damas”. En: Torre de los Lujanes, 12, Madrid, pp. 113-125.

Soria, Martín S. (1957): Esteve y Goya. Valencia: Institución Alfonso el Magnánimo-Diputación Provincial de Valencia.

Torrepalma, condesa de [Francisca María Dávila Carrillo de Albornoz] [1790] (1984): "Instrucciones dadas por la condesa de Torrepalma a las directora de las pupilas". En: Negrín Fajardo, Olegario: Ilustración y educación. La Sociedad Económica Matritense. Madrid: Editora Nacional, pp. 113-119.

Torrepalma, condesa de [Francisca María Dávila Carrillo de Albornoz] (1794): "Elogio de la Reina Nuestra Señora formado por la Excelentísima Señora condesa de Torrepalma, presidenta de la Junta de Señoras de honor y mérito, leído en la Junta pública de distribución de premios de celebrada por la Real Sociedad Económica de Madrid en 25 de enero de 1794". En: Junta General de la Real Sociedad Económica de Madrid, celebrada en las Casas de Ayuntamiento el sábado 25 de enero de 1794. Madrid: Imprenta de Sancha, pp. 40-46.

San Alberto, vizconde de [José Varela de Limia y Menéndez] (1925): Los Directores de la Real Sociedad Económica Matritense de Amigos del País y las Presidentas de la Junta de Honor y Mérito. Madrid: Real Sociedad Económica Matritense de Amigos del País.

Vidal Galache, Florentina y Benicia (1994): Bordes y bastardos. Una historia de la Inclusa de Madrid. Madrid: Compañía Literaria.

Fecha de recepción: 5-VII-2016

Fecha de aceptación: 17-I-2017

Archivo Español de Arte, vol. XCI, n. ${ }^{\circ}$ 361, pp. 70-78, enero-marzo 2018

ISSN: 0004-0428, eISSN: 1988-8511, https://doi.org/10.3989/aearte.2018.06 